\title{
FROM RULING TO PLAY: report of applied research for the development of newsgames
}

DA PAUTA AO PLAY: relato de pesquisa aplicada para o desenvolvimento de newsgames

DE LA PAUTA AL JUEGO: informe de investigación aplicada para el desarrollo de newsgames

\section{Carlos Marciano}

Doctor and Master by the Graduate Program in Journalism at UFSC (Posjor /UFSC). Researcher at the Journalistic Ethics Observatory (objETHOS /UFSC), at the Center for Hypermedia Studies and Production Applied to Journalism (Nephi-Jor) and at the Education, Communication and Media group in the Graduate Program in Education (Edumídia - PPGE/UFSC ). He works as a content producer at the Secretary of Social Communication and Culture of Paraná. He is a professor at the Superior Course of Technology in Digital Games, at Centro Universitario de Brusque - UNIFEBE. carlosnmarciano@gmail.com.

0000-0002-6567-3340

Correspondence: SECRETARIA DA COMUNICAÇÃO SOCIAL E DA CULTURA. Comunicação Social, Palácio Iguaçu, Praça Nossa Senhora de Salette, Centro Cívico, 80.530-909 - Curitiba, PR - Brasil.

Received: 02.16.2021.

Accepted: 04.16.2021.

Published: 07.01.2021.

\begin{abstract}
:
The Newsgames gain more space as a new language of journalism, taking the information through the playfulness of the games. In this sense, stimulating the development of this tool becomes crucial. This article derives from a doctoral thesis that used applied research to establish a methodology for developing newsgames. Thus, it presents a synthesis of the work, highlighting the key concept of the Game Design Document for Newsgames (GDDN), and the method used in the workshop for the planning and development of journalistic games, held at the Universidade Federal de Santa Catarina (UFSC), which brought together professionals from the labor market, undergraduate and graduate students.
\end{abstract}

KEYWORDS: newsgames, applied research, journalism

\section{Introduction}

Before being publicized, an article for radio, TV, print or internet is planned, selected and only then produced. Using games in journalism also follows this logic, requiring planning before putting your hand in the codes.

In order to clarify the horizons about this process of construction of journalistic games, this article will present the method used in the workshop "GDD for newsgames (GDDN)", which was part of the discipline "Special Topics in Journalism XVII - Empirical and Applied Research Questions in Journalism", in which three newsgames were developed.

The subject was taught in 2018 at the Universidade Federal de Santa Catarina (UFSC), targeting undergraduate and graduate journalism students, as well as professionals from the labor market.

This is an applied research based on the active learning methodology proposed by Moran (2013). On that occasion, three methods proposed by the author were used: "project-based learning", in which students were involved with tasks and 
challenges to develop a project; "collaborative learning, among peers", based on the definition of in-person interest groups that shared knowledge to resolve doubts; and "personalized learning", in the sense that the activities were adapted to the rhythm and needs of each group.

In order to systematize this proposal and make it clearer how the workshop was planned, this article is organized into four sections: Concepts and definitions of newsgames; the Game Design Document for Newsgames (GDDN); Methodological description of the workshop; Newsgames developed.

The first two refer to the central theoretical content presented to the students, which conceptualizes, defines and structures the planning of newsgames. The following two expose the characterization and organization of the workshop, as well as the games developed in it.

Thus, by disclosing the paths followed in the workshop "GDD for newsgames (GDDN)", it is hoped that this work will be an initial guide in the development of newsgames, in the sense that other people, journalists or not, can replicate the steps here exposed and thus plan and produce or guide the production of new journalistic games.

\section{Newsgame concepts and definitions}

In an attempt to propose reflections on politics through his games, the Uruguayan journalist and designer Gonzalo Frasca (2003) coined the term newsgaming in mid-2001. Then came a style of game with the proposal to convey the developer's opinion, with the characteristic of political cartoons and cartoons in newspapers.

Adapted to newsgame, the term refers to games whose content originates from news or ongoing events so that, through objectives and mechanics, the player is transported to the pictured scenario and can thus reflect on that theme.

Like Frasca (2003), Sicart (2008) also considers that public debate is present in the dynamics of newsgames. In turn, Treanor and Mateas (2009) reinforce the approximation of journalistic games with political cartoons, but emphasize the need for the graphic and interactive elements of these games to encourage in the player the same positioning of the vehicle on the topic addressed. 


\section{Obsevisto}

Treanor and Mateas (2009) still believe that the relevance of s Newsgames is in persuasive focus of its content, thereby allowing them to continue drawing attention, even if it is no longer highlighted in the press.

The authors illustrate this position citing September $12^{\text {th }}$, a game developed by Gonzalo Frasca and released in 2003, with the aim of causing reflection on the American strategy of carrying out a "surgical bombing" in retaliation for the terrorist attack of September 11, 2001.

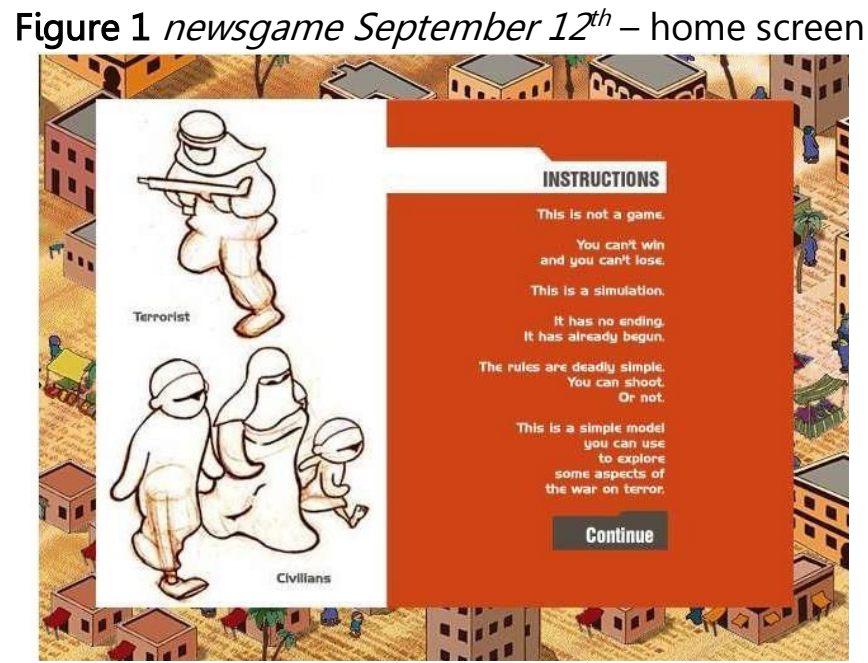

Source: http://www.newsgaming.com/games/index12.htm.

For the authors, a newsgame can fit into more than one genre, as long as its characteristics contemplate the specificities of the different modalities.

When performing a search for newsgames, it is possible to find projects developed both by journalistic vehicles and by independent producers. In the latter case, developers are not always trained in journalism, so they produce the game inspired by a journalistic story, but whose focus is entertainment.

Marciano (2020) argues that newsgames are intended to inform or propose a reflection on the content portrayed, therefore, such games inspired by journalistic content, but focused only on entertainment, do not meet this requirement, being considered by the author as a Game Based on News (JEN).

To establish this differentiation, Marciano (2020) analyzes whether the informative content is present or not within the graphic elements of the game, thus defining three parameters: Direct Audiovisual Presence of the Informative Content (PADCI); Production and Verification Team (EPA); Direct Audiovisual Presence of Sources (PADF). 
The Direct Audiovisual Presence of Information Content (PADCI) aims to identify whether the game focuses on entertainment or presents elements that add something to the original content or theme.

In the case of newsgames, PADCI acts through journalistic information that is "presented in some way within the game (text, videos, photos, illustrations), thus proposing a reflection, extra content or counterpoint on the theme/ information portrayed" (MARCIANO, 2020, p.66).

As the focus of the Game Based on News (JEN) is entertainment, PADCI is not manifest, so that the graphic elements are only references to the journalistic content of inspiration, that is, there is no information in them that add or propose reflection on the thematic addressed.

The Production and Verification Team (EPA) seeks to identify if among the game developers there is someone responsible for the journalistic verification of the content.

In the newsgame development team there is at least one person, usually a journalist, responsible for checking the content, checking the veracity of the facts and defining what will be portrayed and inserted in the game. Developers' names and their respective roles are usually visible in some part of the newsgame intended for credits.

In the production of Games Based on News (JEN), there is no concern to check/verify the content, only a journalistic theme is necessary for reference. Often these games don't have a field with the developers' names on them.

Finally, the Direct Audiovisual Presence of Sources (PADF) is intended to identify whether the game presents the original sources that served as a reference for the topic addressed.

In a newsgame, presenting the informative sources reinforces the journalistic aspect and character, so that the sources are usually presented directly, in some game menu, or through links in the gameplay objects.

In the Game Based on News (JEN), the absence of the source of information signals the priority of entertainment and, eventually, the source that supported the topic is presented. In this sense, even though the graphic and sound elements refer to journalistic material, the player will only understand this reference if he has a previous contact with the content that inspired the game production, unlike newsgames that provide easy access to the original source. 
To ensure that a game is in fact a newsgame, Marciano (2020) recommends that it present the three parameters, but reinforces that the Direct Audiovisual Presence of Information Content (PAD Cl) is the differentiating requirement:

It is not enough just to say on the credits layout that a journalist participated in the development, nor to place the link to the source story in isolation. What distinguishes the newsgame from the Game Based on News (JEN) is the fact that the former presents information that aggregates or proposes some reflection on the reference content, whether they are present in the gameplay or in the internal layouts (MARCIANO, 2020, p. 71).

In addition to understanding these definitions, to develop a newsgame it is necessary to plan and structure the ideas before putting your hands dirty.

That's where the Game Design Document for newsgames(GDDN) proposed by Marciano (2020), a kind of road map for the construction of journalistic games.

\section{The Game Design Document para Newsgames (GDDN)}

Just like the telejournalism page, the Game Design Document for Newsgame (GDDN) helps the team work, structuring what will be present in the game and making it clear at which points the journalistic content will appear.

Associating the definitions of journalistic lead established by Lage (2001) and the ten-page GDD, placed by Rogers (2014), in his proposition, Marciano (2020) structures the Game Design Document for Newsgames (GDD) into 13 topics, briefly described to follow:

1- History (What?): answering the journalist 's first question (What?), this topic details the game's history with a beginning, middle and end, presenting the theme or matter that serves as the basis for the newsgame.

2- Objectives (Why?): as well as the sixth question of the leader (Why?) describes the cause of the fact reported, this topic describes the purpose of the game (educational, commercial, etc.), to which audience it intended and what the player needs to do to complete it.

3- Team and deadline: this item define how many members will participate in the project and their functions, as well as the time available for development. To better divide the tasks, the author recommends that the minimum team be composed of a journalist (responsible for investigating the 
journalistic content and verifying how it is being inserted in the newsgame), a programmer (whose function is to bring the game to life, whether encoding the digital game or making the board, cards and analog game pieces) and an artist (who will develop the game's graphic elements, such as scenarios, characters and sounds).

4- Gameplay and platform (How?): this is one of the most important topics in GDDN, as it will detail the game mechanics, such as movement and actions of characters and enemies, victory and defeat conditions, game style (platform, cards, board, etc), rewards and challenges, as well as where it will be available (PC, browsers, consoles, android, IOS, etc ). The leader's question five (How?) presents the way in which the event occurred. The same way this topic describes all the technical aspects of the game, that is, how it should be developed and played, and where the journalistic information will appear on newsgame.

5- Characters (Who?): in the journalistic role, the second question (Who?) indicates those involved in the matter. Likewise, this GDDN topic should describe who the characters in the game are, including their physical characteristics, personality, actions, and their role in the newsgame storytelling.

6- Enemies: if the newsgame has enemies such as monsters or items that cause damage, they must be detailed in this topic, indicating, among other things, how they are, at what times in the game they appear and how they affect the player's progress (takes lives, subtracts points, etc). It is important to note that in this topic everything that poses difficulty for the player's advancement should be described, that is, a game that does not have enemies in the form of avatars, but has timed phases, has time as an obstacle, being necessary describe here how running the clock can affect newsgame advancement.

7- Game Universe (When?, Where?): this topic should detail the game environment, that is, how the scenarios will be, how many phases the game will have, what their connection, etc. will be. In the journalistic lead, question 3 (When?) is about the moment when the event occurred, while question 4 (Where?) presents the place of the fact. The same logic is described here for 
the newsgame, so that the game's universe will place the player in the time and place where the story takes place.

8- Controls: this topic details the input and output characteristics of the newsgame, that is, which commands the player must execute to interact (press buttons, click, scroll the screen) and what they will correspond to in the game (move the character, move from setting, etc ). It is important to emphasize that if a newsgame is developed for more than one platform, it is essential that this topic describes the form of interaction in each of them (for example, use of joystick to play on PC and touch screen commands for mobile devices).

9- Camera: this topic refers to the player's view of newsgame objects, such as a first or third person view of the game. If there are different views in the newsgame, it is necessary to define here where these changes will occur, for example, in the transition between scenarios.

10-Interface: in this topic it should be described how the visual elements will be arranged on the game screens, such as button order, inventory, position of enemies and items, in addition to the game indication elements, known as HUD $^{1}$ (Heads-Up Display).

11-Cutscenes: this topic deals with videos, texts or animations inserted in the middle of the game to explain or illustrate something in the story. If developers choose to insert them in the newsgame, it should be detailed here in which moments the cutscenes will appear, describe their script, as well as define the tools used for their production and capture.

12-Schedule: with the deadline defined, it is important that developers plan the activities, describing in this topic how the tasks will be divided between the team and the deadline for execution. Good schedule management facilitates the work and guarantees the quality of the newsgame; thus, a weekly followup meeting is recommended, in order to verify that the work is on schedule and solve any unforeseen issues.

13-Budget: having control of expenses in any project is fundamental and in the development of journalistic games it would be no different. If the team

1 Heads- Up Display (HUD) are on-screen markings, known in games as attributes. They serve to place the player inside the game, so that he can follow his progress (amount of life, powers, collected items, timer indicating how much time is left until the game ends, etc.). 
receives funding for the production of the newsgame, it is in this topic that the costs must be detailed, entering in a spreadsheet all expenses, such as labor, equipment, software, space maintenance, publishing and marketing.

Analyzing the Game Design Document for newsgame $s$ (GDDN) proposed by Marciano (2020), it is clear that 13 items can be organized into three groups: Required Topics, Optional topics and Administrative Topics.

Mandatory Topics refer to those items that must be included in the planning of any newsgame, and are directly related to the technical details of the game.

Thus, this group is composed of eight topics: History (What?), Objectives (Why?), Game Universe (Where? When?), Team and Deadline, Controls, Gameplay and Platform (How?), Camera and Interface.

Formed by the items Characters (Who?), Enemies and Cutscenes, the Optional Topics group refers to elements that may or may not integrate the newsgame, depending on the gameplay mechanic chosen by the development team.

For example, a team that wants to develop a newsgame in which journalistic content is presented using card game mechanics does not need to fill in these three items from the Game Design Document for Newsgame s(GDDN), as the game will have none player-controlled character, cutscenes or a minimum time to be played.

Finally, the Administrative Topics group includes the Schedule and Budget items. Even if a newsgame has a big deadline and has no recipe for its development, it is important that the team think about these two items when writing the Game Design Document for Newsgame (GDDN).

They were separated from the others not because they are expendable, but because they refer to administrative aspects of the project, unlike the others that are directly linked to the technical part of the games.

In this sense, doing the exercise of defining a schedule and budget in the GDDN helps to better organize the work, and these two topics will be required if the teams submit the project to a funding notice.

It is important to point out that "a newsgame does not necessarily need to cover all GDDN topics presented here; however, it is necessary that its informative and gameplay structure are well defined" (MARCIANO, 2020, p.86). 
In other words, to be considered a newsgame, it is essential that the journalistic content is clearly present in the game (phases, characters, menus, etc.), in order to propose to the player a reflection, counterpoint or complement to the topic addressed.

The concept of the Game Design Document for Newsgame (GDDN) served as the basis for the Applied Research developed in the workshop format, in the journalism course at the Universidade Federal de Santa Catarina (UFSC).

The description of the activity as well as some of the results will be presented below.

\section{Methodological description of the workshop}

In order to apply the Game Design Document for newsgame s(GDDN) shown above and make the students were planning and produce journalistic games, the development workshop had the audience undergraduate and graduate degrees in journalism, plus of professionals in the labor market.

She was part of the discipline "Special Topics in Journalism XVII - Empirical and Applied Issues in Journalism Research", taught in 2018 at the Federal University of Santa Catarina (UFSC).

The workshop was divided into six meetings, lasting 4 hours each, being taught to 20 students and developed in the computer lab equipped with desktops, overhead projector, blackboard, stable internet connection via network cable and work tables.

In addition to the desktop connected to the overhead projector, which was used in the presentation of students and for teachers' explanation, the following materials were made available to students:

1- form for consultation and identification of newsgame concepts;

2- form for completing the GDDN, containing an explanation of each of the 13 topics;

3- lined sheets, unlined sheets, pencils, erasers, rulers and pens;

4- 8 computers in the lab, all equipped with the Construct 2 software available for the team s could research and develop newsgame.

For the workshop, two objectives were established: 
1- To introduce Game Design Document for Newsgames(GDDN) to determine whether its topics exposed were clear as to the participants get a game plan following them;

2- Assist teams in programming the Construct 2 software so that they could develop at least one of the phases planned in GDDN.

The working method was structured in five parts:

a) presentation of general concepts about the study of games;

b) conceptual presentation of Serious Games and newsgames, the categories proposed by Bogost, Ferrari and Schwaizer (2010) and the stages of development;

c) presentation of the 13 topics of the Game Design Document for newsgame s (GDDN) and differentiation between Newsgames and Game Based on News (JEN);

d) creation of groups so that they could analyze GDDN topics, plan a newsgame from it and use the form as a query and record of what was defined in each topic during planning;

e) assist teams in developing games with Construct 2 software.

At the first meeting of the workshop the students were introduced to the concepts of game studies, definitions Serious Games, besides the concept, categories and process development the newsgames.

Figure 2: cover of the presentation of class 1

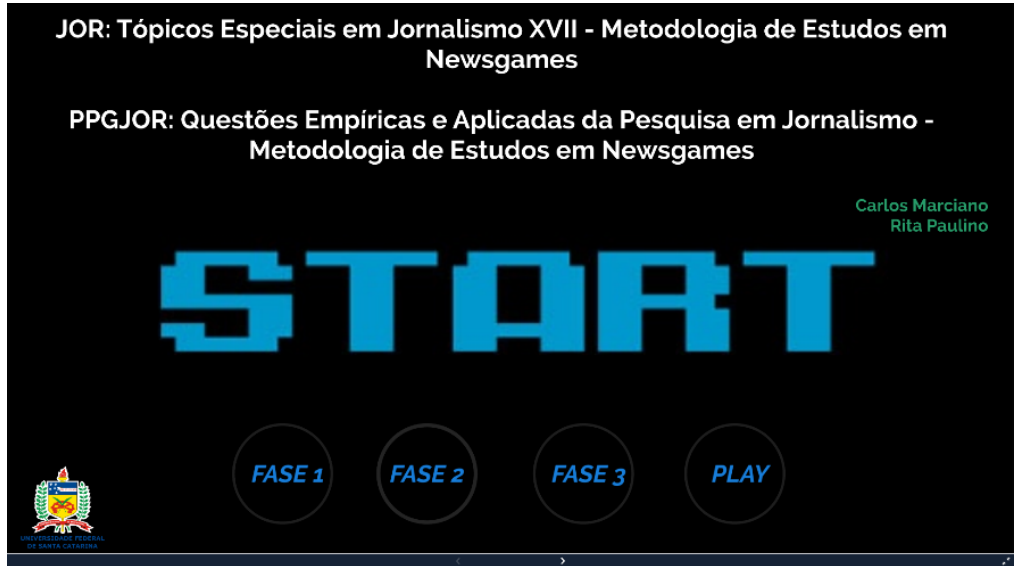

Source: https://prezi.com/view/1rYthrYiBlw3uHH9bEf7/ 
In order to introduce the students to the theme of the next class, at the end of the first class, they were given an exercise in analyzing newsgames.

Figure 3: exercise proposed in the first meeting

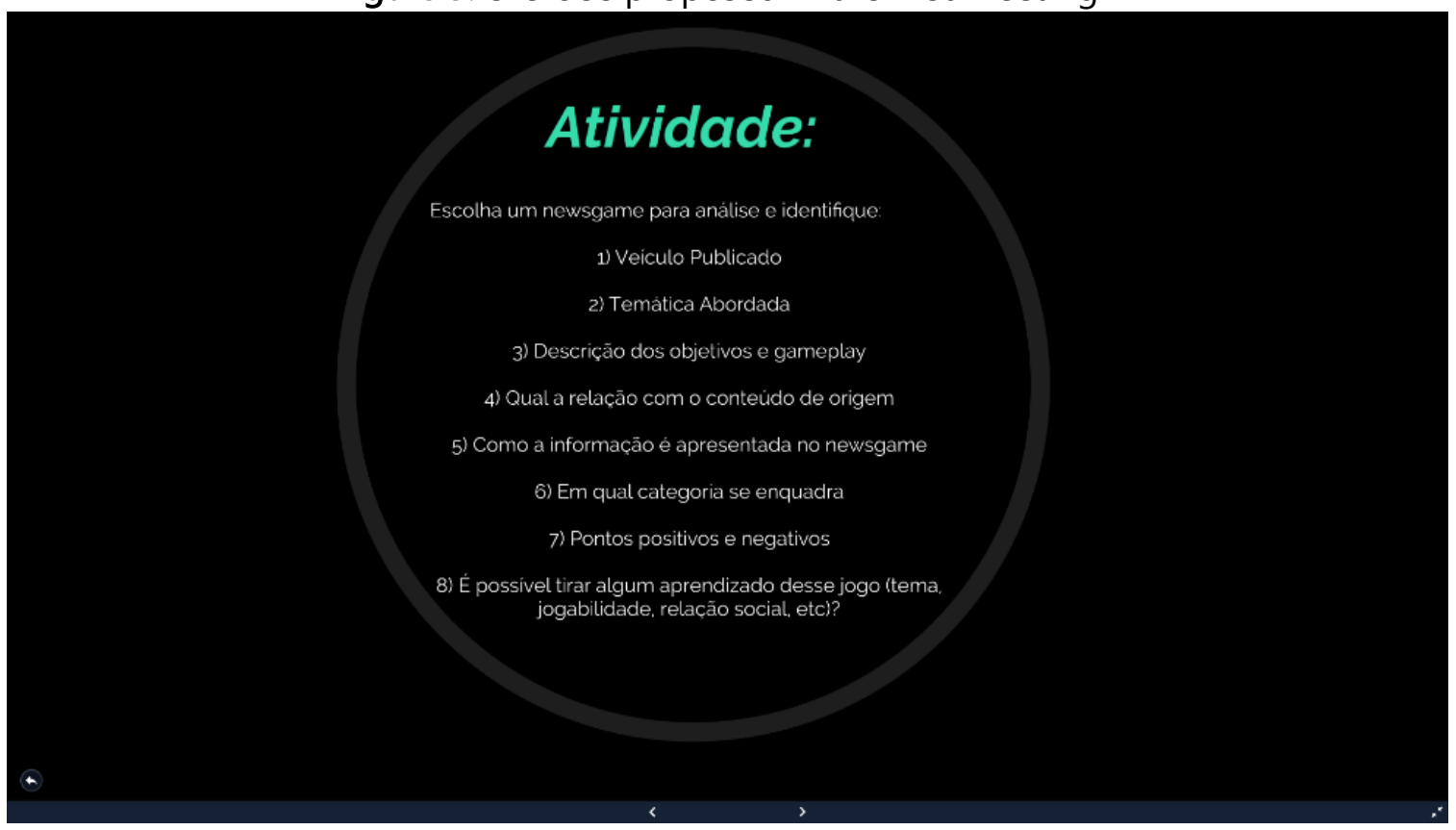

Source: https://prezi.com/view/1rYthrYiBlw3uHH9bEf7/

The Game Design Document for Newsgames (GDDN) was presented to students at the second meeting, as well as the differentiation between Newsgames and Game Based on News (JEN).

Figure 4: cover of the presentation of class 2

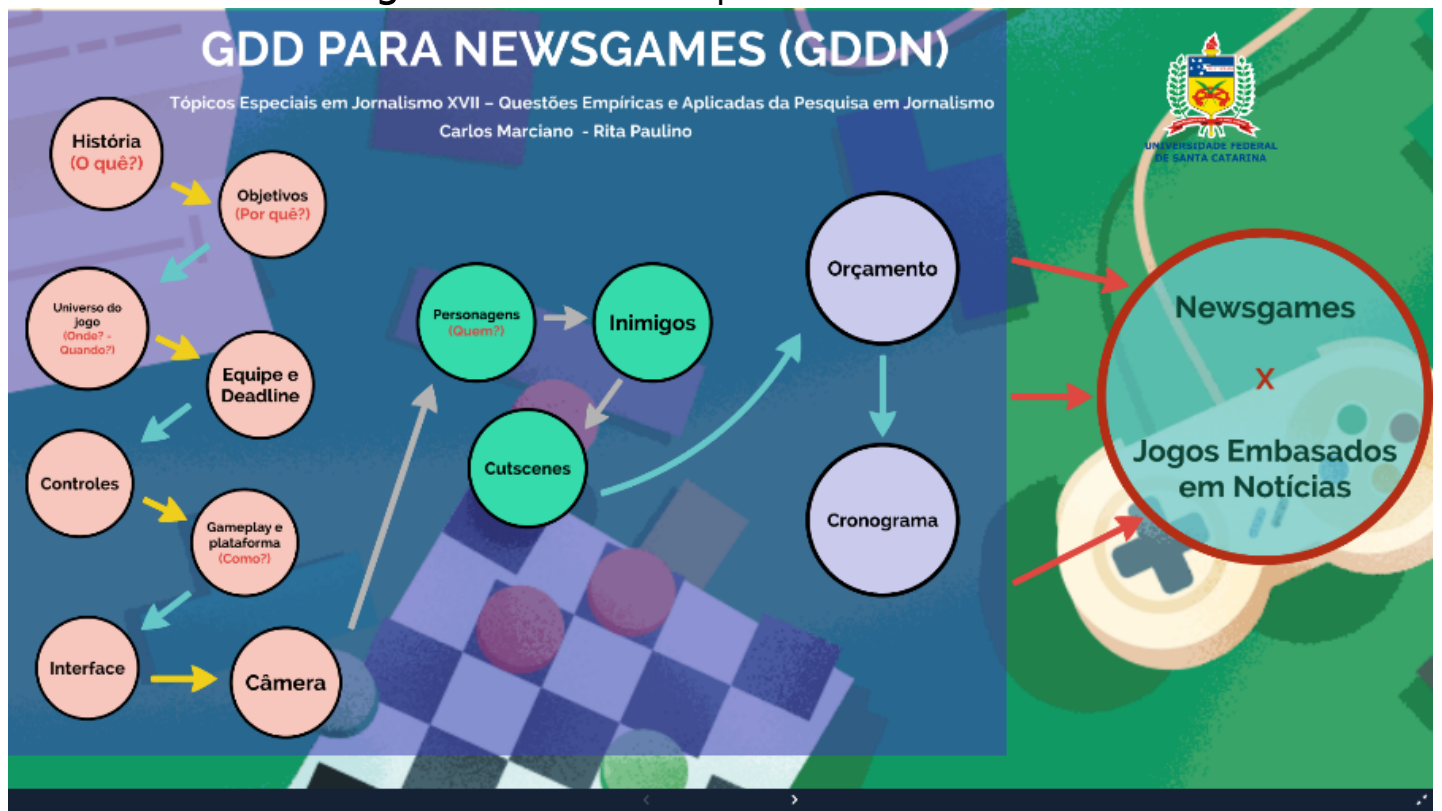




\section{Source: https://prezi.com/view/1rYthrYiBlw3uHH9bEf7/}

After being introduced to the concepts, the following four meetings were made available so that students could develop the newsgames.

Thus, the students were divided into groups, so that each team would need to:

1- choose a theme and develop new journalistic material that would serve as the basis for the project;

2- plan the game, structuring it by filling in the GDDN topics;

3- produce a digital newsgame using Construct 2 software.

In order to standardize and ensure that the products developed were considered newsgames, games should meet six requirements:

a) Menu screen: with the name of the game and at least one button that led to the gameplay screen.

b) Information with game credits: that is, present a screen with the name of the developers and their respective roles.

c) Information about the game: presenting the theme addressed and the context in which the newsgame was developed.

d) Gameplay screen: with at least one complete playable phase and at least one element that referred to the theme covered in the article produced by the team.

e) Win and lose screens: accessed, respectively, when the player won and lost the game.

f) Link to present the report in a new browser tab: this can be through a button or interactive element in the gameplay.

Aware these requirements, the teams gathered for structuring of GDDN and encoding of newsgames and presented the following three projects developed: SOS Hercílio, Fact-checking O Jogo - Fato ou Fake, and Mete a Colher.

\section{Developed newsgames}

After knowing the concepts and structuring the newsgame on GDDN, each team started the development of the idealized game using the Construct 2 software for coding. 
In practice, the lecturers presented Construct 2 to the students, explained how it worked and only then did each team dedicate itself to the respective project, closely following the professors to resolve doubts related to conceptual and coding aspects.

It is important to emphasize here that any game development software could be used in this stage of the methodology, so Construct 2 was chosen by the workshop's teachers because it was, at the time, a free tool, with a friendly and easy-to-use interface, as it does not require prior knowledge of any programming language.

In this sense, the presentation of the games below aims to illustrate the results and focuses on the content and form of each newsgame, thus allowing to present the methodology developed in the workshop without restricting its application to a specific tool.

\section{SOS Herćlio²}

Developed by students Letícia Beilfuss, Luciana Leão, Luíz Cláudio, Ricardo Aoki and Thiago Malkowski, the newsgame had as its theme the Hercílio Luz bridge, a postcard of the city of Florianópolis.

Both the article and the newsgame tell the story of the construction of the bridge, inaugurated in 1926, highlighting the imbroglio behind its restoration.

The menu screen corresponds to requirement " $a$ ", as it presents the name of the game centered and the buttons "Play", "Read News" and "About".

Figure 5: SOS Hercílio newsgame-Menu screen

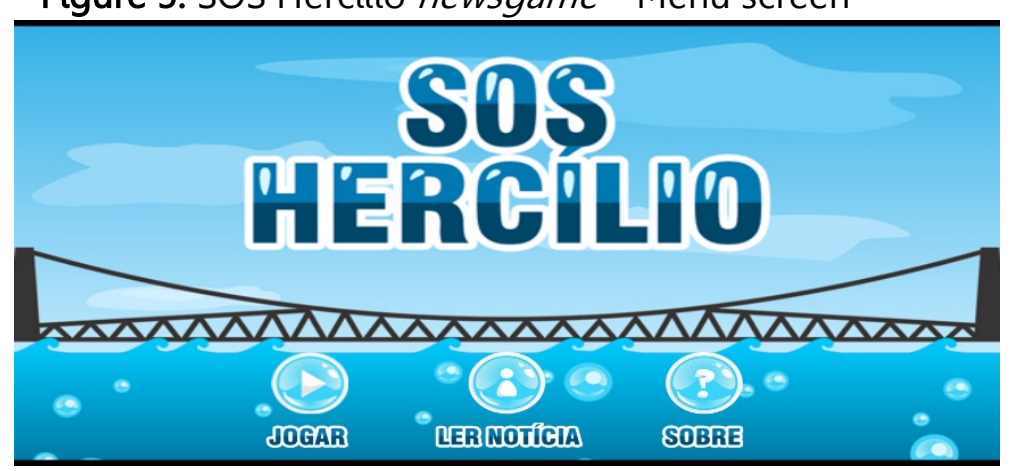

Source: https://aokittos.itch.io/sos-hercilio

Although the material that served as the basis for the newsgame was not presented in an external link, the " $f$ " requirement was also met, as it is fully presented within the game, being accessed when the player clicks the "read news" button. 


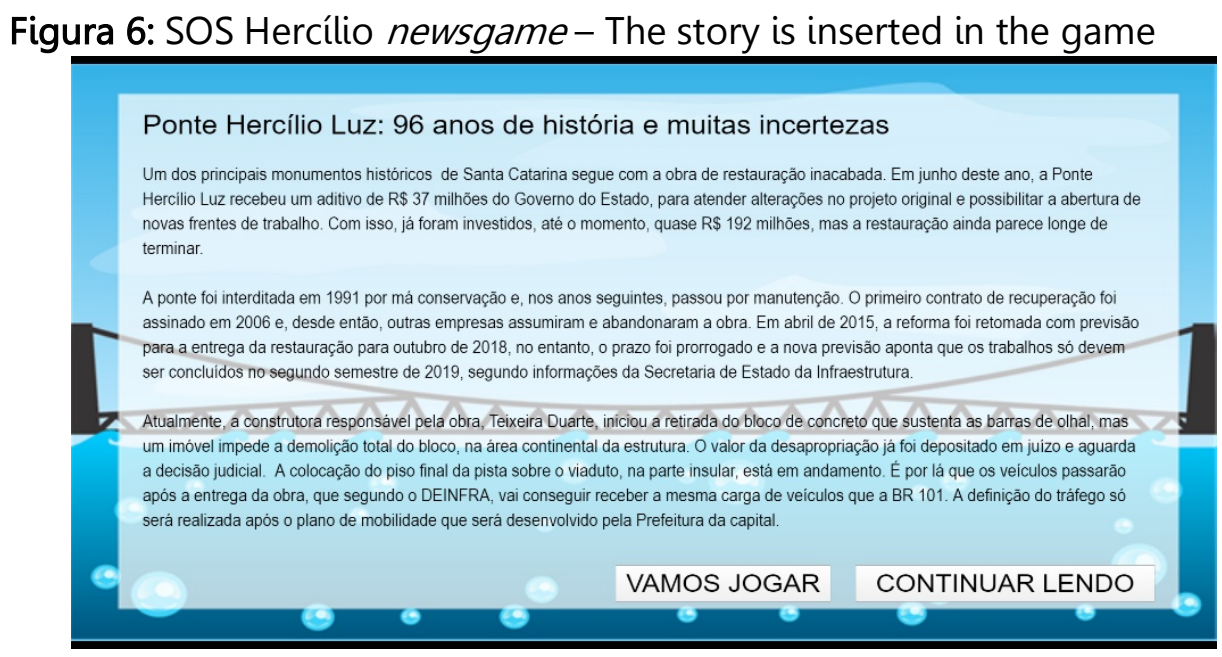

Source: https://aokittos.itch.io/sos-hercilio

On the gameplay screen, before the phase starts, the player is presented with an instruction screen, indicating the controls and the objective of the game: open access to Florianópolis by turning on all the lamps on the bridge.

Figure 7: SOS Hercílio newsgame-Instructions screen

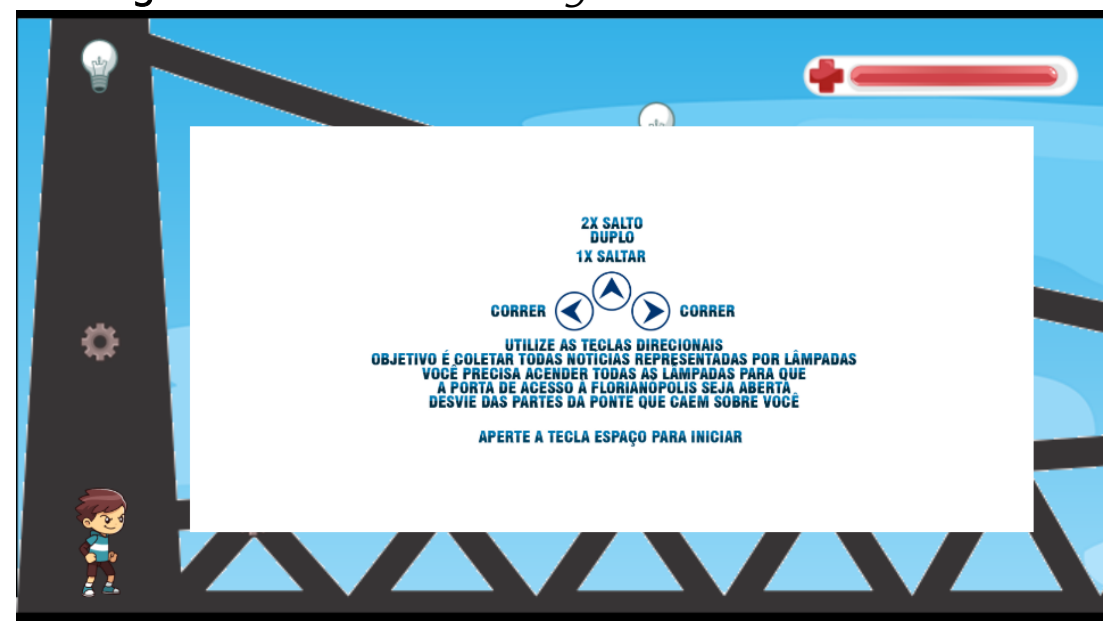

Source: https://aokittos.itch.io/sos-hercilio

As seen in Figure 8, in the control of a character representing a tourist walking across the bridge, the player needs to avoid being hit by the gears (1) and at each lighted light (2) the game pauses and complementary information to the matter appears in the upper part of the screen (3), thus meeting requirement " $d$ ". It is noteworthy that, contrary to what appears in the lower left corner (4), to continue the game it is necessary to press the space key, not the "b" key. 
Figure 8: SOS Hercílio newsgame - Gameplay screen: items and information

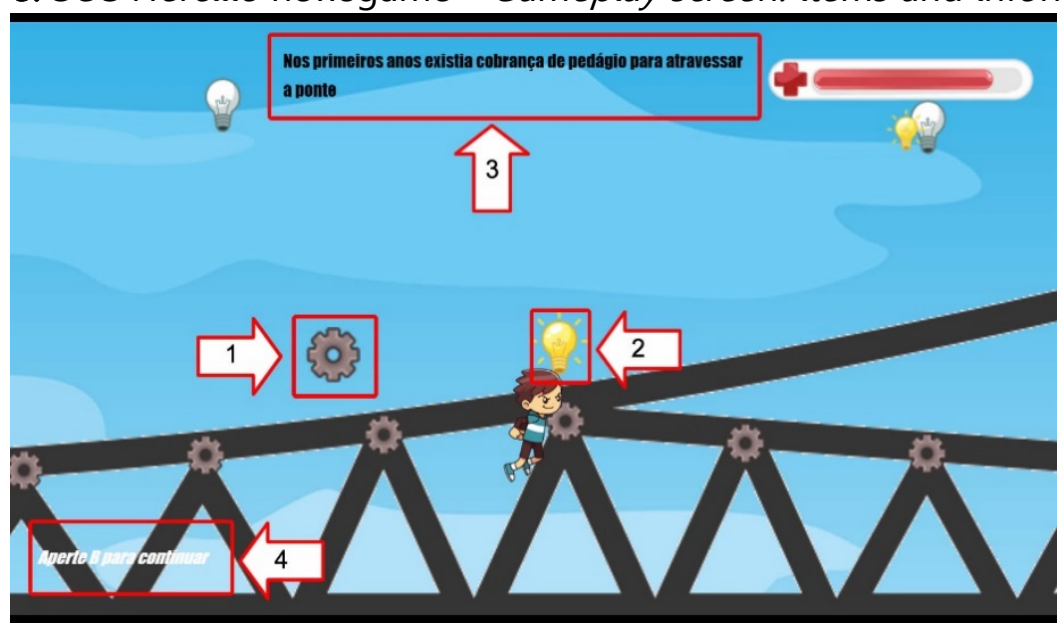

Source: https://aokittos.itch.io/sos-hercilio

Each gear that hits the player takes some of the character's life and if it reaches zero the game ends and the defeat screen appear. If he manages to light all 14 lights the victory condition is reached and the player is directed to the victory screen. Thus, the " $\mathrm{e}$ " requirement is also met.

Figure 9: SOS Hercílio newsgame- Defeat screen

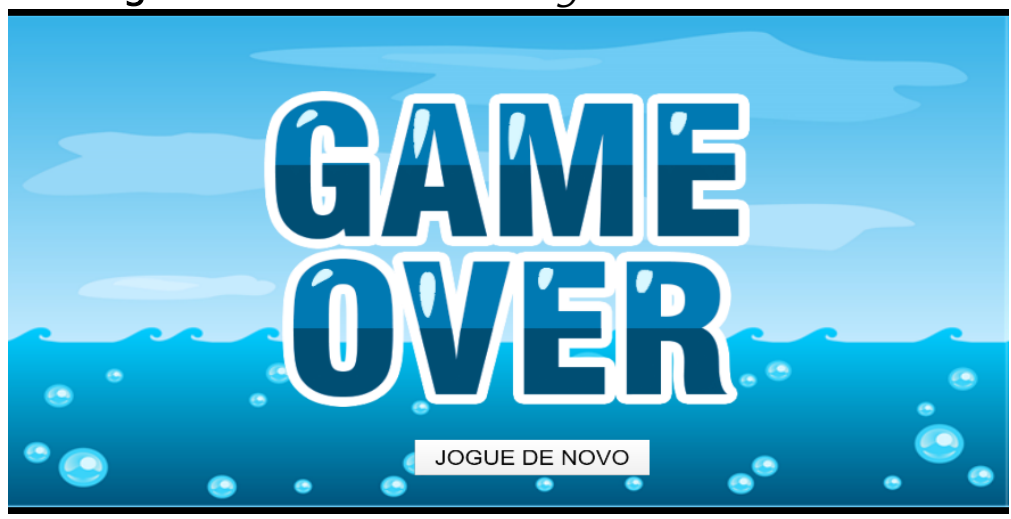

Source: https://aokittos.itch.io/sos-hercilio 


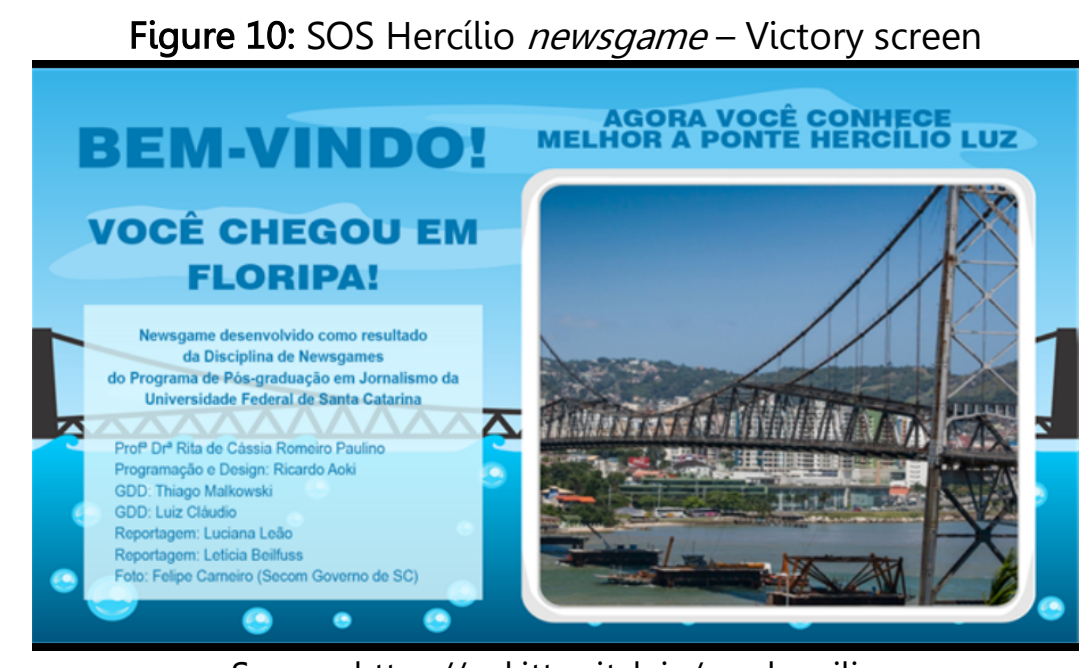

Source: https://aokittos.itch.io/sos-hercilio

It is also on this screen that the developers' information and the context in which the game was produced are present, thus meeting requirements " $b$ " and " $c$ ".

\section{Fact-checking O Jogo - Fato ou Fake ${ }^{3}$}

Inspired by information checking agencies, the newsgame developed by students Ana Carla Pimenta, César Rosati, Manoela Bonaldo, Thuane de Oliveira and Yanne Roberto, puts the player in the shoes of a journalism intern, with the objective of verifying the information passed on by boss Mary.

The men screen u newsgame both meets the requirement "a" as the requirement " $f$ " because it shows the name of the game, the button that takes you to the gameplay screen and also a symbolized button for a magnifying glass, which opens a new browser window in which you can read the multimedia content that supports the game. 


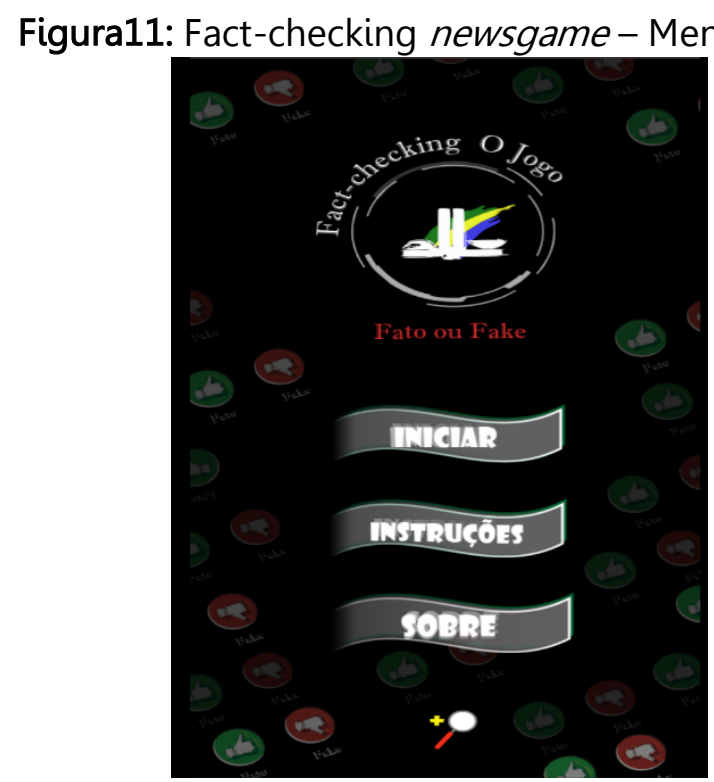

Source: https://marciano.itch.io/fact-checking

Still in the menu, it is possible to access the instructions screen that places the player in the story. In turn, by clicking "on" it is directed to the screen where you can check the name of the team members, their functions and the context in which the newsgame f hi developed, thus meeting the requirements "b" and "c".

Figure 12: Fact-checking newsgame- About screen (left) and instructions (right)
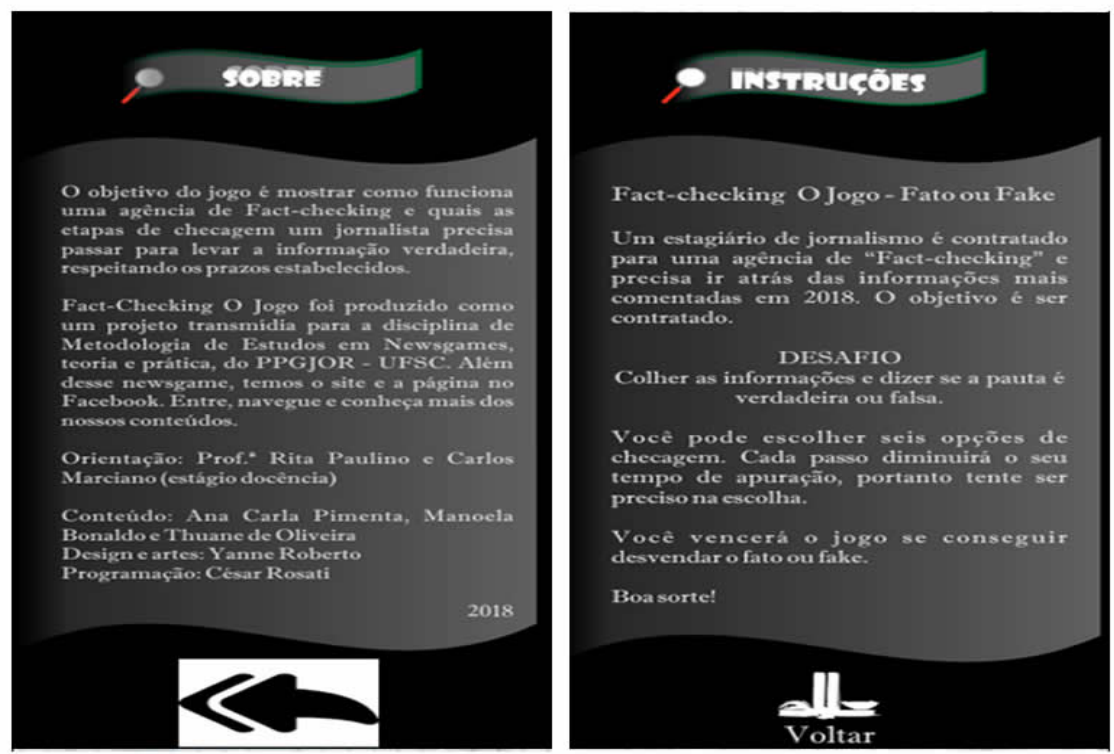

Source: https://marciano.itch.io/fact-checking

Developed using quiz mechanics, the game consists of receiving the agenda from editor-in-chief Maria and verifying the content before the deadline (1) runs out. For this, 
the player can check in six (2) different places, each of which reduces the counting time. It is possible to read the agenda again whenever necessary (3), but the button to send the answer (4) will only be active when there are two hours before the deadline.

Figure 13: Fact-checking newsgame - Screening screen (left) and source speech (right)
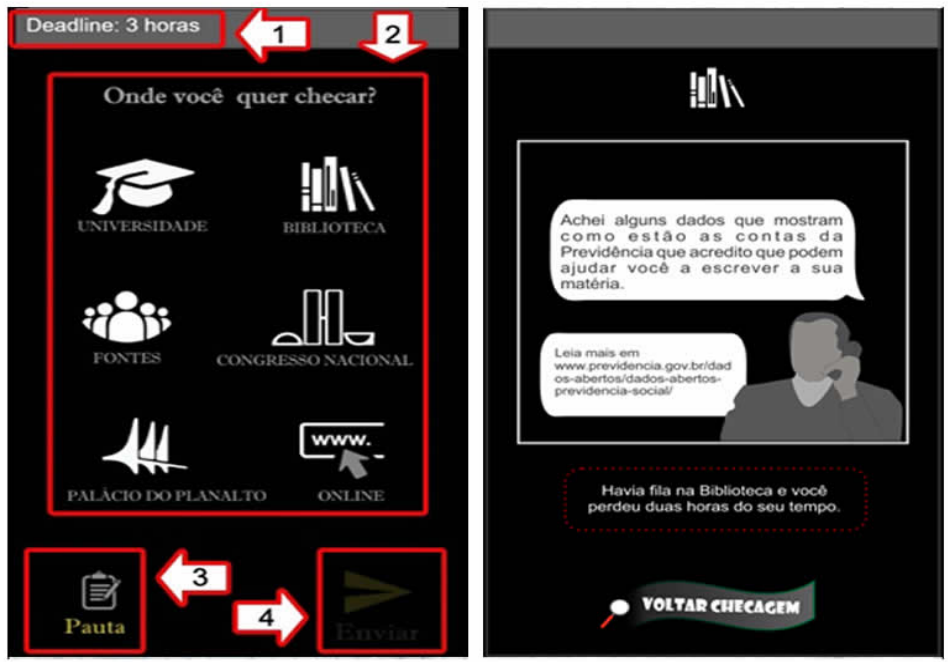

Source: https://marciano.itch.io/fact-checking

If the player misses the deadline or considers false information to be true, and vice versa, he then reaches the defeat condition. If he makes the correct count, the victory condition is reached. Thus, the " $\mathrm{e}$ " requirement was also met.

Figure 14: Fact-checking newsgame - Wrong answer screen (left) and promotion (right)
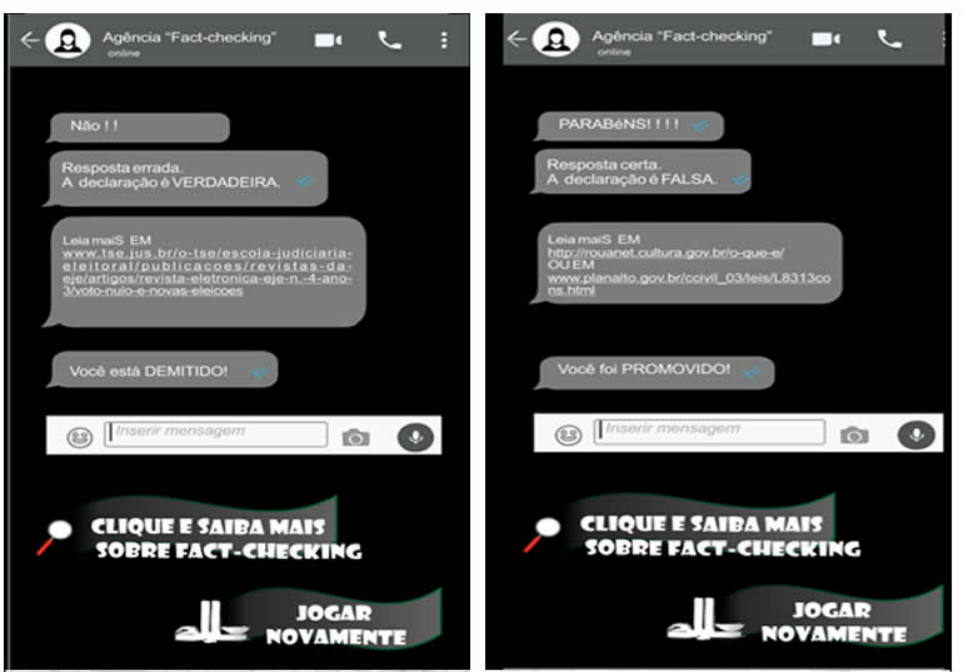

Source: https://marciano.itch.io/fact-checking 
Requirement " $d$ " was achieved insofar as the theme chosen by the team is represented in the newsgame graphics, as well as in the texts of the guidelines and information given by the sources.

\section{Mete a Colher ${ }^{4}$}

Developed by students Ana Paula Bourscheid, Ânderson Silva, Frederico de Carvalho, Mariane Pires Ventura and Paulo José Mueller, this newsgameaddresses violence against women as a theme.

In a scenario that refers to the edge of Florianópolis, the player controls a character who witnesses situations of violence against women, and it is then necessary to decide whether he ignores it and goes ahead or "takes the spoon", interfering in the case.

In addition to meeting requirement "a", presenting the title of the game and the button to play it, the menu also includes the requirement " $f$ ", by presenting the button "read the article" which, if clicked, opens in a new browser tab the story that supports the newsgame.

Figure 15: Mete a Colher newsgame - Menu Screen

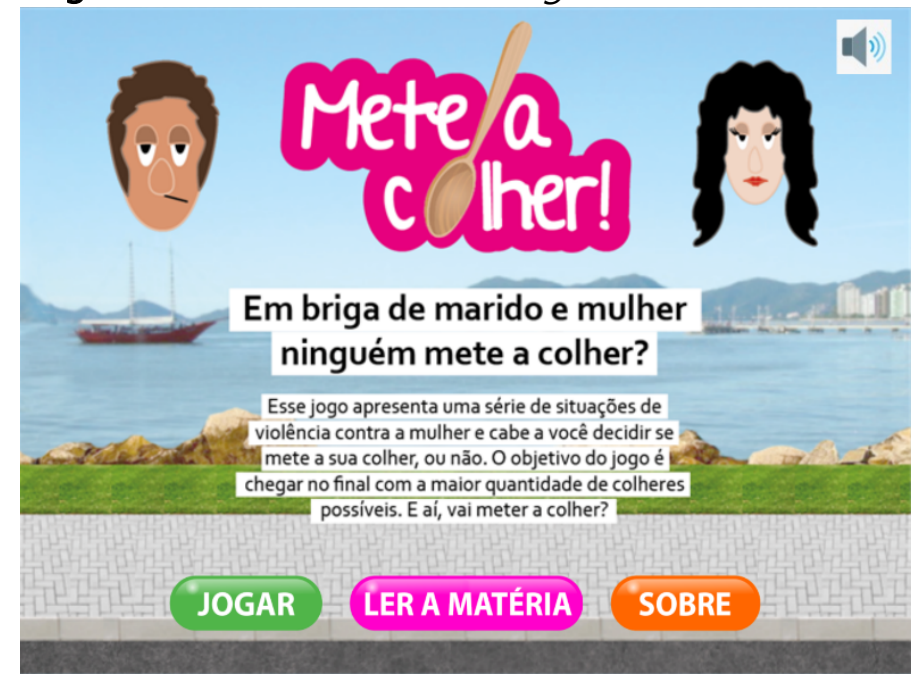

Source: https://marciano.itch.io/ng-meteacolher

On the over screen, it is possible to observe the fulfillment of requirement " $c$ ", as the text signals the context in which the newsgame was developed. Also on this screen, it is observed that requirement " $b$ " was partially fulfilled, as the names of the developers are described, but their functions are not specified. 
Figure 16: Mete a Colher newsgame - About screen

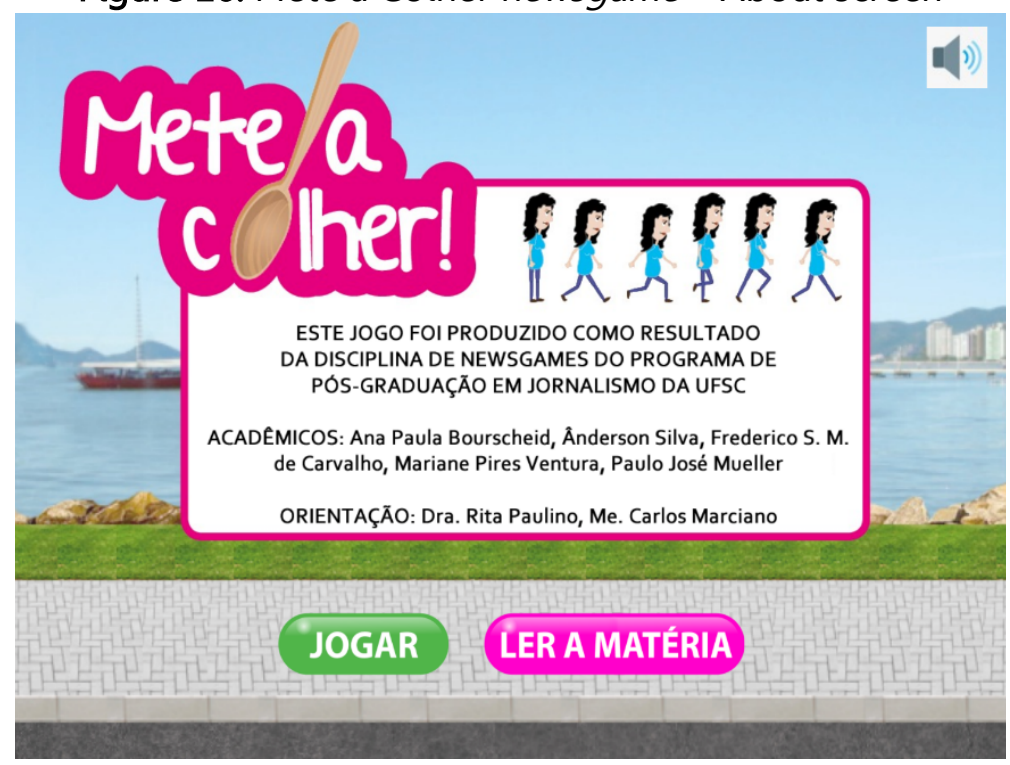

Source: https://marciano.itch.io/ng-meteacolher

By clicking play it is possible to select a male or female character, but both interact in the same way in gameplay. In a game style that mixes platform and quiz mechanics, the player walks through the scene until he comes across a situation in which a woman is suffering violence.

At this point a screen shows the situation and asks if the player wants to ignore or interfere. Choosing the first option, he continues the game as usual, but before it appears a text with statistics on violence against women.

Figure 17: Mete a Colher newsgame-Choice screen

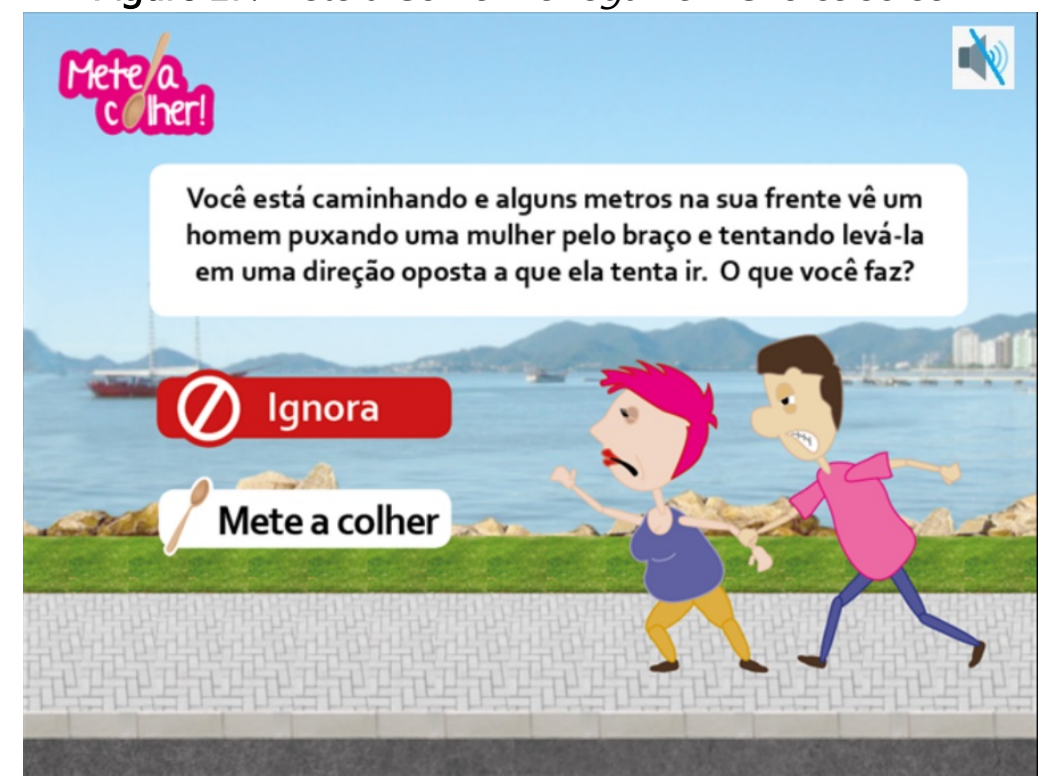


Figure 18: Mete a Colher newsgame - Stats appear when skipping

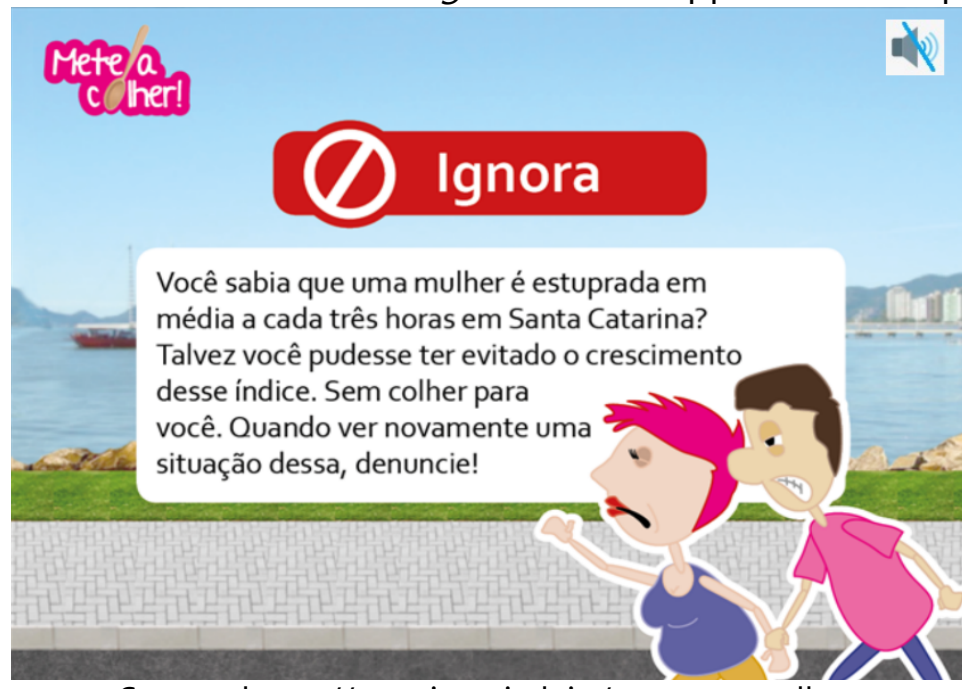

Source: https://marciano.itch.io/ng-meteacolher

However, if the player chooses to interfere, he is presented with four possible actions. If you choose the wrong option, the next screen will indicate the error and show the correct alternative.

Figure 19: Mete a Colher newsgame - Options screen (left) and error alert (right)

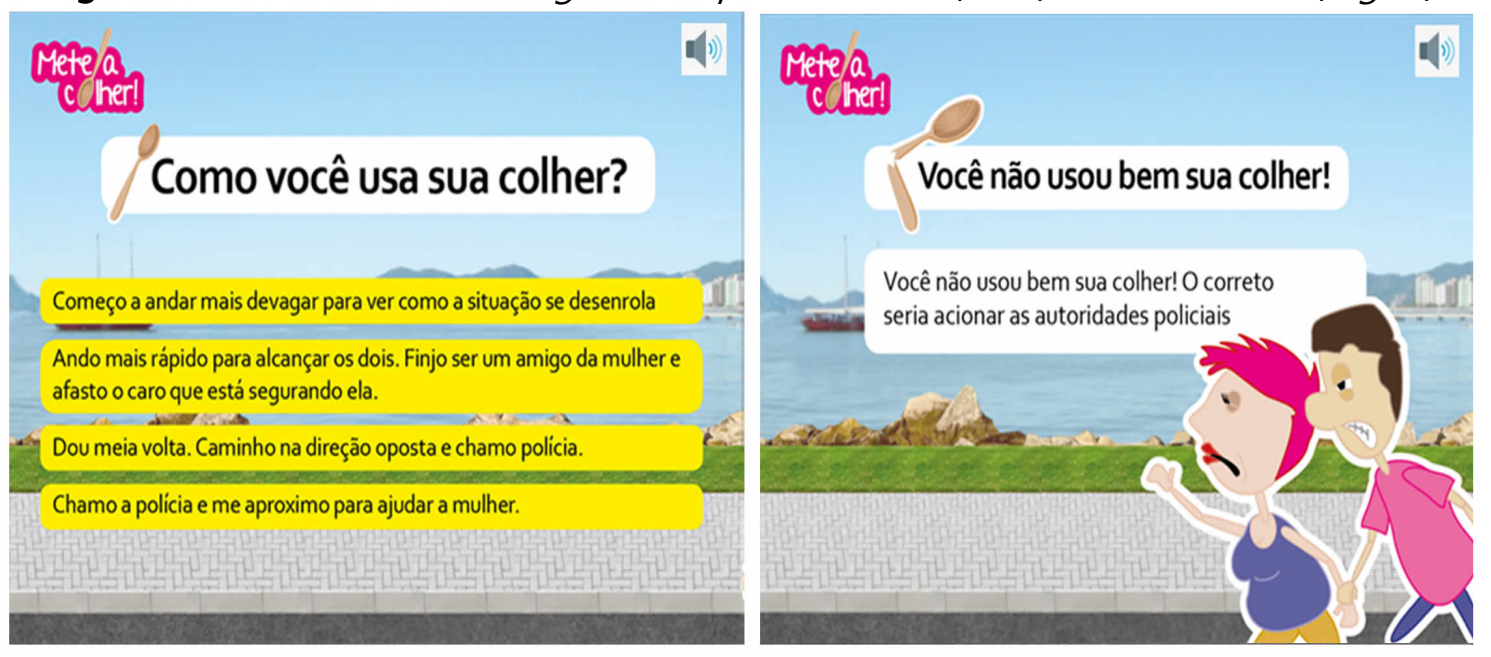

Source: https://marciano.itch.io/ng-meteacolher

If he gets the question right, the next screen indicates the right one and a spoon is highlighted at the top of the screen (1). There are five scoops in all, so he starts with one, and he can earn the other four if he succeeds in his answers. 
Figure 20: Mete a Colher newsgame - When the player gets it right, he gets a spoon
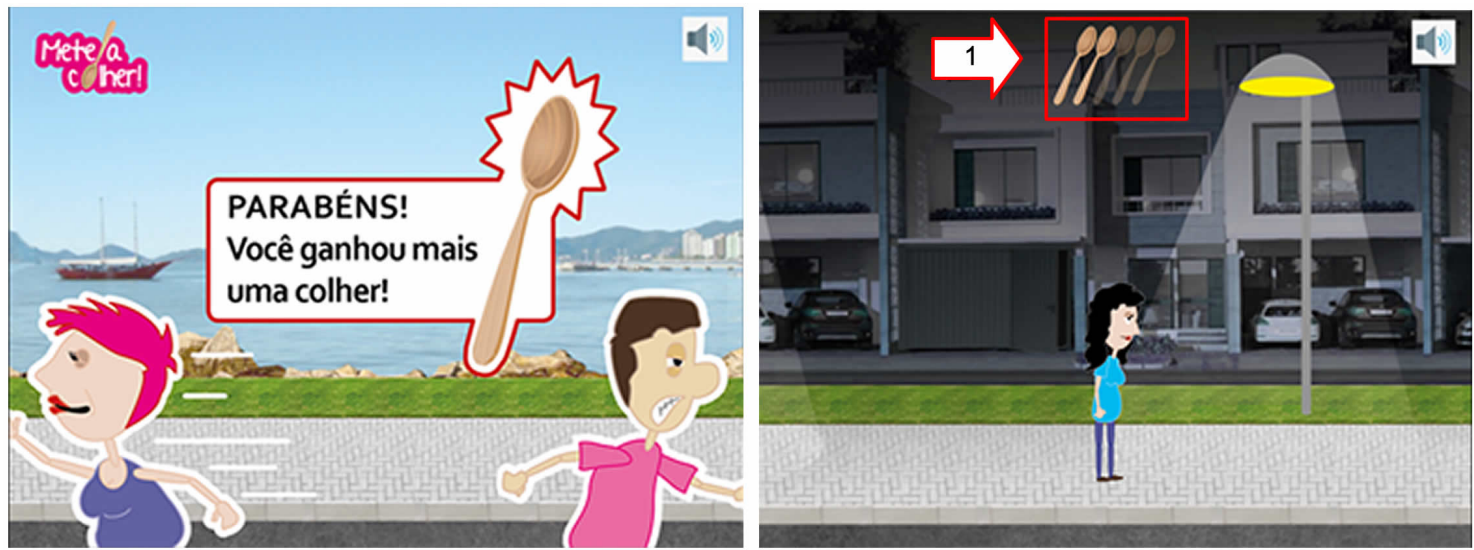

Source: https://marciano.itch.io/ng-meteacolher

After witnessing the four situations, the player is directed to the final screen of the newsgame, regardless of whether he got it right, wrong, or ignored the questions. The amount of hits is indicated by the number of scoops highlighted the top.

Through the text just below the spoons, it is possible to see which of the four categories the player fits into, according to the result obtained.

Figure 21: Mete a Colher newsgame - Final screen

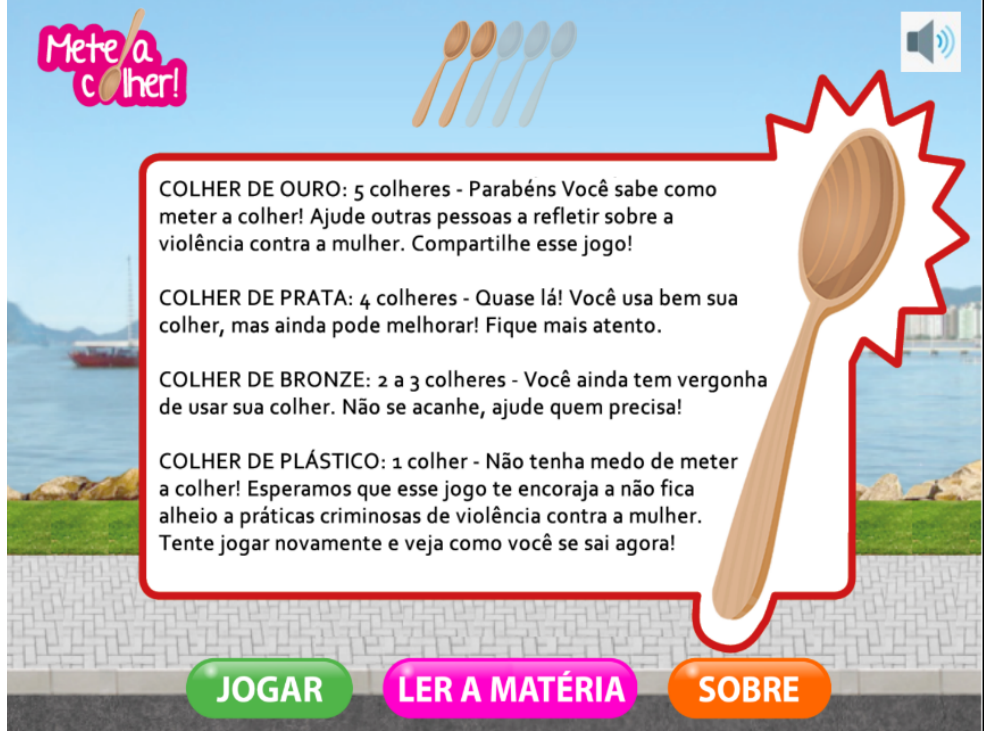

Source: https://marciano.itch.io/ng-meteacolher

Requirement " $\mathrm{d}$ " is achieved in the newsgame, as the chosen theme is represented in the texts and graphics. Although the game does not have win or lose screens, it can be said 
that the "e" requirement was also met, as it is up to the player to analyze his result and see if he won or lost the game.

If we compare two pain players, the one who got the most scoops came out victorious, however in this newsgame the developers chose not to put victory or defeat conditions precisely for the player to reflect on their performance.

Those who managed to get a few scoops can review their actions to improve the result, while those who managed to collect all five of them can pass on learning about the topic.

\section{Final considerations}

The technological advancement allows the journalistic information gets further and further away, however, also brings new challenges such as the fight to combat the fakes news and the search for transmitting the contents of increasingly dynamic and attractive way.

In this scenario, it is evident that it is no longer just a matter of transcribing subjects from traditional media to digital, it is necessary to understand this ecosystem, unveil new tools, and integrate journalism with other areas.

Using newsgames in this context is promising, but it is necessary to keep in mind that "a newsgame that only entertains, that does not present information or proposes reflection on the topic addressed is just a game" (MARCIANO, 2020, p.39).

Before putting your hand in the codes too much, it is necessary to reflect on how to do it, following a consistent logic so that the journalistic content is not succumbed to the fun.

As previously reported, the workshop presented here had the following objectives:

a) present the Game Design Document for newsgames (G DDN) to determine whether its topics exposed were clear as to the participants get a game plan following them;

b) assist the teams with programming in the Construct 2 software so that they could develop at least one of the phases planned in GDDN.

The basis of the results it was found that both were achieved, since the students understand the differences between Newsgames and Game Based on News (JEN), developed and managed GDDN schedule at least one stage newsgame proposed. 
The applied research portrayed in this work aims to break the stereotype that the idea of inserting games in journalism is interesting, but the practice seems distant and complex: the expressed theory and the games developed from it show that it is possible to produce quality newsgames, independently if you are an academic or a professional in the market.

It is also worth noting that the development of newsgames in the workshop took place in two stages:

1 - game planning through filling GDDN topics;

2 - game development using Construct 2 software.

If the workshop method is replicated, it is recommended that those involved follow this step and the first structure the game from the GDDN.

Thus, even if there is no member in the working group with knowledge of software for game development (such as Construct, Unity, Unreal, etc), the theoretical basis of the newsgame will be ready and this qualified professional can be found later.

After all, if it is not possible to code the newsgame, its systematization through GDDN is also valid.

To develop newsgames is no easy task, requires discipline, commitment and dedication. The methodology presented here aims precisely to make this path less painful, giving direction to those who wish to plan, guide and develop journalistic games

Thus, it is expected that, taking as a guide the structure of the Game Design Document for Newsgame(GDDN) and the method exposed here, striving to replicate it, the result is the planning or conception of an innovative and playful journalistic tool, taking information beyond entertainment.

\section{References}

BOGOST, I.; FERRARI, S.; SCHWEIZER, B. (2010). Newsgames Journalism at Play. ed. Massachusetts: Massachusetts Institute of Technology.

FRASCA, G. (2003). Simulation versus Narrative: Introduction to Ludology. In: Wolf, Mark J. P; Perron, Bernard. The Video Game Theory Reader. New York: Routledge, pp. 221-235. Recuperado em 28 março, 2021, de: <https://goo.gl/NwXmsN>

LAGE, N.(2001). Ideologia e Técnica da Notícia. 3. ed. Florianópolis: Insular/UFSC.

MARCIANO, C. N. (2020). Da pauta ao play: proposta metodológica para o planejamento e desenvolvimento de newsgames. Tese (Doutorado em Jornalismo) Universidade Federal de Santa Catarina. Florianópolis, p.434.

MORAN, J.(2021). Metodologias ativas para uma aprendizagem mais profunda. 2013. Recuperado em 21 março, 2021, de: < https://goo.gl/Jn3duj> 
ROGERS, S.(2014). Level up: the guide to great video game design. United Kingdom: John Wiley \& Sons.

SICART, M.(2008). newsgames. Theory and Design. International Conference on Entertainment Computing. Pittsburgh.

TREANOR, M., MATEAS, M. (2009). Newsgame. Procedural Rhetoric Meets Political Cartoons. Brunel University, London, 2009. Recuperado em 3 março, 2021, de: < https://www.researchgate.net/publication/255590174_Newsgames_Procedural_Rh etoric_meets_Political_Cartoons> 


\section{Crevisto Observatóno}

\section{RESUMO:}

Os newsgames ganham cada vez mais espaço como uma nova linguagem do jornalismo, levando a informação através da ludicidade dos jogos. Nesse sentido, estimular 0 desenvolvimento dessa ferramenta torna-se crucial. Este artigo deriva da tese de doutorado que utilizou-se da pesquisa aplicada para estabelecer uma metodologia para desenvolvimento de newsgames. Assim, é apresentada aqui uma síntese do trabalho, ressaltando o conceito chave do Game Design Document para Newsgames (GDDN), além do método utilizado na oficina para o planejamento e desenvolvimento dos jogos jornalísticos, realizada na Universidade Federal de Santa Catarina (UFSC), que uniu profissionais do mercado de trabalho, estudantes de graduação e pós-graduação.

PALAVRAS-CHAVES: newsgames, pesquisa aplicada, jornalismo
e-ISSN no $2447-4266$

Palmas, v. 7, n. 3, p. 1-23, jul.-set., 2021 http://dx.doi.org/10.20873/uft.2447-4266.2021v7n3a3en

\section{RESUMEN:}

Los juegos de noticias están ganando cada vez más espacio como un nuevo lenguaje del periodismo, trayendo información a través de la diversión de los juegos. En este sentido, estimular el desarrollo de esta herramienta se vuelve crucial. Este artículo deriva de una tesis doctoral que utiliza la investigación aplicada para establecer una metodología para el desarrollo de newsgames. Así, aquí se presenta una síntesis del trabajo, destacando el concepto clave del Game Design Document para Newsgames (GDDN), además del método utilizado en el taller de planificación y desarrollo de juegos periodísticos, realizado en la Universidad Federal de Santa Catarina (UFSC), que reunió a profesionales del mercado laboral, estudiantes de pregrado y posgrado.

PALABRAS-CLAVES: newsgames, investigación aplicada, periodismo 